\title{
Minimal Invasive Surgery for Gastroesophageal Reflux Disease and Hiatus Hernia-Our Experience: A Case Series with Review of Literature
}

\author{
Rafique Umer Harvitkar ${ }^{1} \quad$ Abhijit Joshi \\ ${ }^{1}$ Department of Surgery, Dr. L.H. Hiranandani Hospital, Powai, \\ Mumbai, Maharashtra, India \\ 2Department of General \& Laparoscopic Surgery, Dr. L.H. \\ Hiranandani Hospital, Powai, Mumbai, Maharashtra, India \\ Int J Recent Surg Med Sci 2021;7:64-71.
}

\author{
Address for correspondence Rafique Umer Harvitkar, MS, MRCS \\ UK, Department of Surgery, Dr. L.H. Hiranandani Hospital, Powai, \\ Mumbai 400076, Maharashtra, India \\ (e-mail: dr_rafique639@yahoo.com).
}

\author{
Abstract \\ Keywords \\ - laparoscopic \\ fundoplication \\ - gastroesophageal \\ reflux disease \\ - OGD scopy \\ - hiatus hernia
}

Introduction Laparoscopic fundoplication (LF) has almost completely replaced the open procedure performed for gastroesophageal reflux disease (GERD) and hiatus hernia $(\mathrm{HH})$. Several studies have suggested that long-term results with surgery for GERD are better than a medical line of management. In this retrospective study, we outline our experience with LF over 10 years. Also, we analyze the factors that would help us in better patient selection, thereby positively affecting the outcomes of surgery.

Patients and Methods In this retrospective study, we identified 27 patients (14 females and 13 males) operated upon by a single surgeon from 2010 to 2020 at our institution. Out of these, 25 patients ( 12 females and 13 males) had GERD with type I HH and 2 (both females) had type II HH without GERD. The age range was 24 to 75 years. All patients had undergone oesophago-gastro-duodenoscopy (OGD scopy). A total of 25 patients had various degrees of esophagitis. Two patients had no esophagitis. These patients were analyzed for age, sex, symptoms, preoperative evaluation, exact procedure performed (Nissen's vs. Toupet's vs. cruroplasty + gastropexy), morbidity/mortality, and functional outcomes. They were also reviewed to examine the length of stay, length of procedure, complications, and recurrent symptoms on follow-up. Symptoms were assessed objectively with a score for six classical GERD symptoms preoperatively and on follow-up at 1-, 4- and 6-weeks postsurgery. Further evaluation was performed after 6 months and then annually for 2 years.

Results 14 females (53\%) and 13 males (48\%) with a diagnosis of GERD (with type $\mathrm{I} \mathrm{HH}$ ) and type II HH were operated upon. The mean age was 46 years (24-75 years) and the mean body mass index (BMI) was 27 (18-32). The range of duration of the preoperative symptoms was 6 months to 2 years. The average operating time dropped from 130 minutes for the first 12 cases to 90 minutes for the last 15 cases. The mean hospital stay was 3 days (range: $2-4$ days). In the immediate postoperative period, $72 \%$ $(n=18)$ of the patients reported improvement in the GERD symptoms, while $2(8 \%)$ patients described heartburn (grade I, mild, daily) and 1 (4\%) patient described bloating (grade I, daily). A total of 5 patients (20\%) reported mild dysphagia to solids in the published online June 16, 2021
DOI https://doi.org/

$10.1055 / \mathrm{s}-0041-1731115$ ISSN $2455-7420$

\footnotetext{
(C) 2021. Medical and Surgical Update Society.

This is an open access article published by Thieme under the terms of the Creative Commons Attribution-NonDerivative-NonCommercial-License, permitting copying and reproduction so long as the original work is given appropriate credit. Contents may not be used for commercial purposes, or adapted, remixed, transformed or built upon. (https://creativecommons.org/licenses/by-nc-nd/4.0/). Thieme Medical and Scientific Publishers Pvt. Ltd. A-12, 2nd Floor, Sector 2, Noida-201301 UP, India
} 
first 2 postoperative weeks. These symptoms settled down after 2 to 5 weeks of postoperative proton-pump inhibitor (PPI) therapy and by adjusting consistency of oral feeds. There was no conversion to open, and we observed no perioperative mortality. There were no patients who underwent redo surgeries in the series.

Conclusion LF is a safe and highly effective procedure for a patient with symptoms of GERD, and it gives long-term relief from the symptoms. Stringent selection criteria are necessary to optimize the results of surgery. Experience is associated with a significant reduction of operating time.

\section{Introduction}

Gastroesophageal reflux disease (GERD) is defined as a condition that results from abnormal and repetitive exposure of the esophagus and/or the respiratory tract to gastric contents, which causes symptoms and/or complications. These complications may include esophagitis, peptic stenosis, Barrett's esophagus, and a diverse number of conditions in the respiratory tract such as cough, mild dyspnea, chronic bronchitis, etc. ${ }^{1,2}$ GERD affects 10 to 20 percent of the Western population and 5 to 10 percent of the Asian population. Long-term therapy with proton-pump inhibitors (PPIs) can be effective in treating symptoms of reflux esophagitis and its sequelae. ${ }^{3,4}$ However, $80 \%$ of patients have a recurrence of severe GERD within 4 to 6 months of cessation of medical treatment with PPIs. ${ }^{5}$ Thus, antireflux surgery is a good alternative long-term therapeutic option. The added advantage of avoiding long-term PPI therapy is the prevention of its associated side effects such as Clostridium difficile infection, pneumonia, dementia, micronutrient deficiencies such as those of calcium, vitamin B12 and magnesium, acute interstitial nephritis, chronic kidney disease, osteoporosis with pathological fractures, adverse drug interaction with antiplatelet agents, gastric fundic gland polyps, gastric neuroendocrine tumor, colon cancer, etc. ${ }^{5,6}$ With the advent of laparoscopic surgery, the volumes of antireflux surgeries have grown enormously. Although most authors have mentioned favorable long-term results, some have questioned the efficacy and durability of this procedure. ${ }^{6}$ In this retrospective study, we state our experience of laparoscopic fundoplication (LF) over the last 10 years.

\section{Patients and Methods}

In this retrospective study, we identified 27 patients (14 females and 13 males) with a mean age of 46 years (range 24-75 years.), who underwent laparoscopic antireflux and type II hiatus hernia $(\mathrm{HH})$ repair surgery at our institution, from 2010 to 2020, performed by a single surgeon. All patients had undergone oesophago-gastro-duodenoscopy (OGD scopy). A total of 25 patients had endoscopically proven esophagitis, whereas two did not. The symptoms on presentation were pyrosis $80 \%(n=22)$, regurgitation $40 \%(n=11)$, dysphagia $30 \%(n=8)$, epigastric or retrosternal pain and abdominal bloating 20\% ( $n=5)$, and nonspecific symptom of cough $8 \%(n=2)$ patients. They were analyzed for esophagitis by OGD scopy and for esophageal motility and lower esophageal sphincter (LES) pressure by upper gastrointestinal (UGI) manometry (-Table 1). They were also analyzed for age, sex, symptoms, preoperative evaluation, operative approach, exact procedure performed (Nissen's vs. Toupet's vs. cruroplasty + gastropexy), morbidity/mortality, and functional outcomes. They were also reviewed to examine the length of stay, length of procedure, complications, and recurrent symptoms on follow-up. The patient demographics and early postoperative follow-up information are summarized (-Table 2).

Table 1 Preoperative investigations

\begin{tabular}{|c|c|c|c|c|c|}
\hline Investigation & Characteristics & All & $\begin{array}{l}\text { Normal weight } \\
\text { (BMI 19-24) }\end{array}$ & $\begin{array}{l}\text { Overweight } \\
\text { (BMI 25-29) }\end{array}$ & $\begin{array}{l}\text { Obese } \\
(\mathrm{BMI}>30)\end{array}$ \\
\hline \multirow{4}{*}{$\begin{array}{l}\text { Upper Gl-scopy } \\
\text { esophagitis } \\
\text { grade }\end{array}$} & a. Grade I-II & 21 patients (79\%) & $2(9.5 \%)$ & $16(80 \%)$ & $3(10.5 \%)$ \\
\hline & b. Grade III & 2 patients $(7 \%)$ & - & $1(50 \%)$ & $1(50 \%)$ \\
\hline & c. Grade IV-V & 2 patients (7\%) & - & $2(100 \%)$ & - \\
\hline & d. No esophagitis & 2 patients $(7 \%)$ & - & $1(50 \%)$ & $1(50 \%)$ \\
\hline \multirow[t]{3}{*}{$\begin{array}{l}\text { Oesophageal } \\
\text { manometry }\end{array}$} & $\begin{array}{l}\text { a. Low-LES and normal oesophageal } \\
\text { motility }\end{array}$ & 23 patients (85\%) & $7(30 \%)$ & $14(61 \%)$ & $2(9 \%)$ \\
\hline & b. Low LES and low oesophageal motility & 2 patients $(7.5 \%)$ & $1(50 \%)$ & $1(50 \%)$ & - \\
\hline & $\begin{array}{l}\text { c. Normal LES and normal oesophageal } \\
\text { motility }\end{array}$ & 2 patients $(7.5 \%)$ & - & $1(50 \%)$ & $1(50 \%)$ \\
\hline \multirow{2}{*}{$\begin{array}{l}\text { OGD length of } \\
\text { type I hiatus } \\
\text { hernia }\end{array}$} & a. More than $3 \mathrm{~cm}$ & 20 patients $(80 \%)$ & $5(25 \%)$ & $14(70 \%)$ & $1(5 \%)$ \\
\hline & b. Less than 3 cm & 5 patients $(20 \%)$ & $1(20 \%)$ & $3(60 \%)$ & $1(20 \%)$ \\
\hline
\end{tabular}

Abbreviations: GI, gastrointestinal; LES, lower esophageal sphincter; OGD, oesophago-gastro-duodenoscopy; BMI, body mass index. 
All patients were on PPIs preoperatively for variable periods ranging from 8 to 16 weeks. The dose of the PPIs was titrated as per the severity of the symptoms (up to $120 \mathrm{mg} /$ day), given for a minimum of 8 weeks. Duration of symptoms ranged from 6 months to 2 years. Patients with a satisfactory initial response to PPI therapy, but with symptom recurrence on its cessation, were subjected to further evaluation (OGD scopy and UGI manometry). The clinical indications for further diagnostic evaluation and operative intervention were as follows: volume reflux, recurrent reflux post cessation of long-term PPI therapy, and nocturnal reflux in those willing to stop PPIs.

Those with endoscopic signs of GERD with low LES pressures and type I HH and those with type II HH were included in this study. We did not see any type III HH patients in the study period. In our pre-operative protocol, a contrast enhanced computed tomography of the chest and upper abdomen is mandatory for types II \& III HH patients, though not so for type I HH patients. The severity of esophagitis on OGD scopy was graded by the Savary-Miller classification. Patients with severe chronic, comorbid diseases, making them unfit for general anesthesia (American Society of Anesthesiologists [ASA] classification system score III/IV), short esophagus, esophageal peristaltic pathology, OGD scopy negative, OGD scopy positive but with normal LES pressures on manometry, and primary PPI nonresponders were excluded from our study. The salient features of some of our patients on pre- and postoperative diagnostic investigations such as X-ray chest, contrast-enhanced CT chest, OGD-scopy, and barium swallow are depicted in (-Fig. $\mathbf{1}$ ).

Table 2 Patient demographics and early postoperative follow-up information

\begin{tabular}{|c|c|c|}
\hline S. no. & Characteristics of patients & Numbers \\
\hline 1 & Total number of patients & 27 patients \\
\hline 2 & Age range & 24 to 75 years old \\
\hline 3 & Sex ratio (M :F) & $13(48 \%): 14(52 \%)$ \\
\hline 4 & Type of hiatus hernia (I:II) & 25 (93\%): $2(7 \%)$ \\
\hline 5 & Mean duration of symptoms & 16 weeks \\
\hline 6 & $\begin{array}{l}\text { Operating time } \\
\text { First } 12 \text { cases } \\
\text { Next } 15 \text { cases }\end{array}$ & $\begin{array}{l}130 \text { minutes } \\
90 \text { minutes }\end{array}$ \\
\hline \multirow[t]{3}{*}{7} & $\begin{array}{l}\text { a. Nissen's Fundoplication } \\
\text { (posterior } 360 \text { degree) }\end{array}$ & 23 patients $(85 \%)$ \\
\hline & $\begin{array}{l}\text { b. Toupet's Fundoplication } \\
\text { (posterior } 270 \text { degree) }\end{array}$ & 2 patients $(7.5 \%)$ \\
\hline & c. Cruroplasty + gastropexy & 2 patients $(7.5 \%)$ \\
\hline \multirow[t]{5}{*}{8} & Follow-up 1-4 weeks & \\
\hline & i. Improvement in GERD & 18 patients $(72 \%)$ \\
\hline & ii. Heartburn & 2 patients $(8 \%)$ \\
\hline & $\begin{array}{l}\text { ii. Non-specific symptoms } \\
\text { of cough/bloating }\end{array}$ & 1 patients (4\%) \\
\hline & iii. Dysphagia for solids & 5 Patients (20\%) \\
\hline
\end{tabular}

Abbreviation: GERD, gastroesophageal reflux disease.
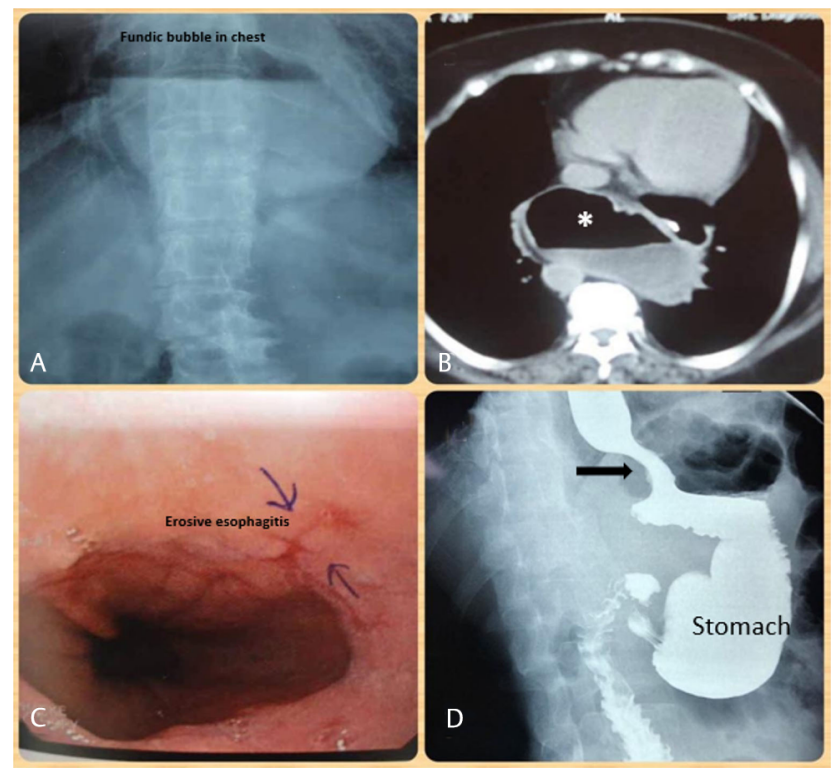

Fig. 1 Preop. investigations. (A) X-ray chest of type II hiatus hernia $(\mathrm{HH})$ showing fundic bubble in chest, (B) contrast-enhanced CT chest of Type II HH showing stomach behind the heart in the chest (white asterisk), (C) oesophago-gastroduodenoscopy (OGD scopy) of type I HH showing grade I-II esophagitis, (D) post laparoscopic Nissen's barium swallow, showing the $360^{\circ}$ wrap in perfect position (black arrow).

At the time of writing this paper, all the patients who were past their last postoperative outpatient department (OPD) follow-up visit were interviewed telephonically with a standard questionnaire. Patients were asked to score six specific GERD symptoms of heartburn, regurgitation, bloating, dysphagia, epigastric or retrosternal pain, and cough. Each symptom was scored as follows: 0-none, 1-mild, 2-moderate, and 3-severe.

Two patients died 5 and 9 years after our surgery, due to myocardial infarction. Patients were followed-up at 1-, 4and 6 weeks postsurgery. Further evaluation was performed after 6 months and then annually for 2 years. Those patients who failed to physically follow up at 6 months, 1 year and/ or 2 years (long term follow-up) were telephonically interviewed with the same aforementioned questionnaire. Those patients who on long term follow-up visits complained of any of the typical GERD symptoms were put on an empiric 15 day PPI regime. If symptoms persisted beyond this, they were advised to get a barium swallow done to check the position of the wrap.

Ours was a retrospective study of hospital inpatient records, OPD data, and information obtained from the telephonic questionnaire.

\section{Operative Technique}

Preoperative anesthesia checkup (PAC) was performed in all the patients. Antibiotic prophylaxis of ceftriaxone (1-1.5 g intravenous [IV]), as per the hospital's antibiotic policy, was administered just before the induction of the anesthesia. In all our laparoscopic antireflux surgeries, the patient is placed in a supine reverse Trendelenburg position with legs split up 
and the operating surgeon standing between the legs. The monitor is placed at the head end of the patient to the patient's left side facing the operating surgeon. Pneumoperitoneum is established by closed technique through the Veress needle. A standard five trocar technique is used. The first optic trocar $(10 \mathrm{~mm})$ is inserted at the level of the junction of the upper two-thirds and lower one-third of the xiphisternum to umbilicus line, slightly to the left of the midline. Four additional ports, right midclavicular ( $5 \mathrm{~mm})$, subxiphoid $(5 \mathrm{~mm})$, left midclavicular $(12 \mathrm{~mm})$, and left anterior axillary $(5 \mathrm{~mm})$ are inserted under vision along the subcostal line. The procedure begins with an incision of the gastrohepatic omentum and entry into the lesser sac. The dissection is then extended cephalad toward the right crus of the diaphragm. The posterior parietal peritoneum over the right crus is incised and the esophagus dissected away from it. Great care is taken to avoid injury to the posterior vagus nerve and hepatic branches of the vagus nerve. Circumferential esophageal mobilization is performed after the creation of a retroesophageal window. The stomach is mobilized along with the upper one-third of its greater curvature up to the esophagus. Crurorrhaphy is performed with interrupted 2-0 polypropylene sutures. The number of inter-crural sutures taken during crurorrhaphy depends on the width of the crural defect $(-$ Fig. 3C). We follow the general principle that one should be able to just about completely open a $5 \mathrm{~mm}$ non traumatic laparoscopic curved dissector between the posterior aspect of the esophagus and the uppermost inter-crural stitch. This ensures that the crurorrhaphy is neither too tight, nor too lax. Adequacy of fundic mobilization is evaluated and confirmed by a "shoeshine" maneuver (-Fig. 3D). A tension-free floppy fundal wrap of anterior length 2 to $3 \mathrm{~cm}$ is then fashioned after the division of the upper short gastric vessels. The floppiness of the wrap is evaluated and confirmed by easy lifting up of the wrap with a nontraumatic $5 \mathrm{~mm}$ instrument ( $\boldsymbol{- \text { Fig. }} \mathbf{2 A}$ ). At least three to four interrupted 2-0 polypropylene stitches are taken to complete the Nissen's wrap. The lowest stitch includes the anterior wall of the esophagus in suture bite. The wrap is fixed to the right crus with three interrupted polypropylene 2-0 stitches. In the Toupet's wrap, the fundic lips are sutured to the esophageal musculosa on both sides with 2-3 interrupted 2-0 polypropylene sutures, thereby fashioning a posterior $270^{\circ}$ wrap ( $\bullet$ Fig. 2B). In Type II HH ( - Fig. 2C) patients with normal LES pressures, a gastropexy is performed after cruroplasty, in place of a fundal wrap. The gastropexy is performed by suture fixation of the anterior stomach wall to the anterior parietes by $2-0$ polypropylene using six separate sutures ( - Fig. 2D). As already mentioned, we perform crurorrhaphy, that is, suture approximation of both the crurae of the diaphragm in patients with type I HH. However, in patients with type II HH, given the large size of the crural defect, we prefer to further buttress the crurorrhaphy with a dual mesh prosthesis (Goretex, parietex, polyurethane, etc.) cut to optimum size, and given a semicircular cut in the middle of its superior border, to accommodate the esophagus in it. After optimum lay, the said mesh prosthesis is suture fixed to the crurae. Thus, we prefer cruroplasty over crurorrhaphy in type II HH patients. For type II HH

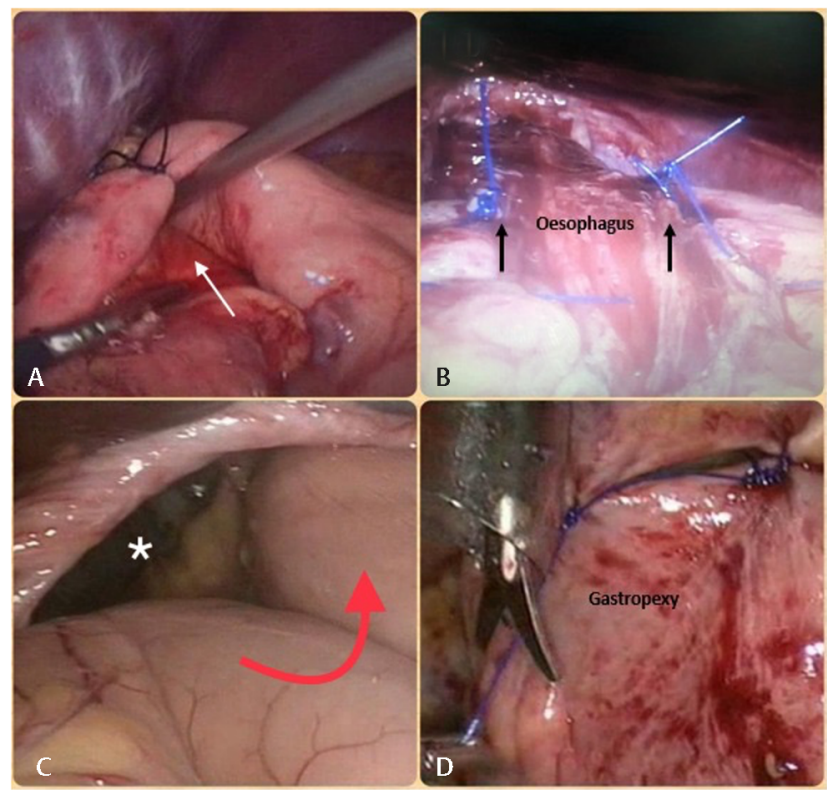

Fig. 2 Operative pictures. (A) Demonstration of a floppy Nissen's wrap (white arrow). (B) Toupet's wrap. (C) Type II hiatus hernia with mesentero-axial gastric volvulus (red arrow) and wide crural defect (white asterisk). (D) Gastropexy-anterior gastric wall being suture fixed to the parietes.
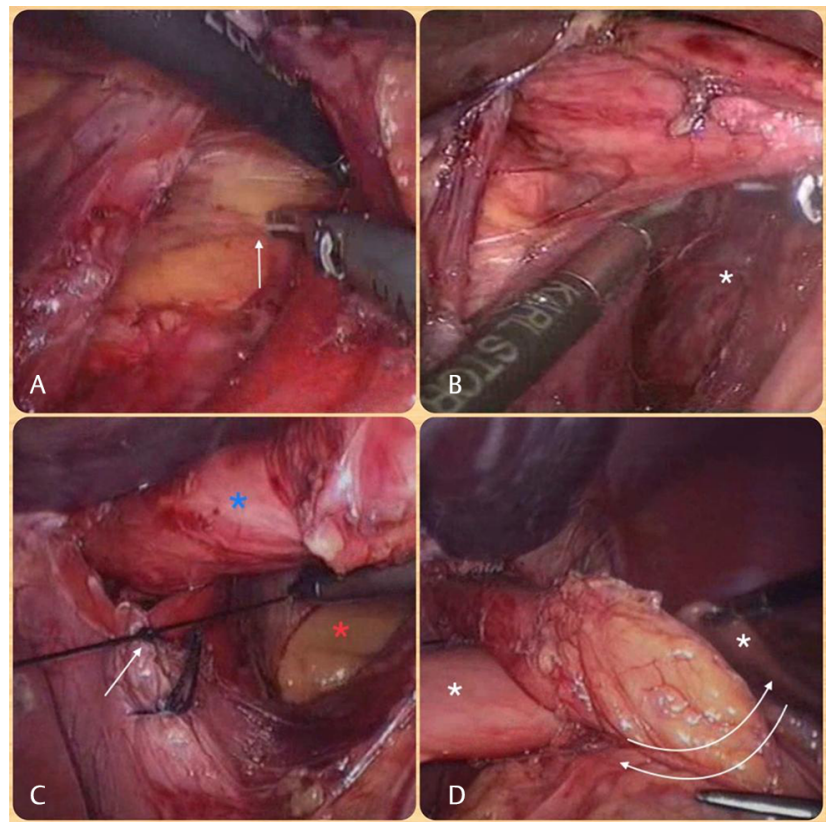

Fig. 3 Operative pictures. Laparoscopic fundoplication. (A) Mediastinal dissection (white arrow). (B) Creation of retro-esophageal window (white asterisk). (C) Crurorrhaphy (white arrow) after adequate mobilization of abdominal esophageal length (blue asterisk) and creation of retro-esophageal window (red asterisk), (D) shoeshine maneuver.

patients who have low LES pressures on manometry but no obvious sliding component, we prefer to perform a fundoplication instead of a gastropexy, along with the cruroplasty. Incidentally, both our type II HH patients had normal LES pressures and no esophagitis. All our patients are kept nil per oral for the first 24 hours with a nasogastric tube (NGT) in 
situ, kept open, and aspirated regularly. The NGT is clamped on day one after the surgery and clear liquids started orally. On day 2, the NGT is removed, and a semisolid diet is started orally. The patients are advised to continue this diet for the first 2 weeks. They are discharged on day 3 of the surgery. A solid diet is resumed 2 weeks after the surgery.

\section{Results}

On preoperative OGD scopy, 25(93\%) patients had GERD with type I hiatus hernia $(\mathrm{HH})$ and $2(7 \%)$ patients had type II $\mathrm{HH}$ without GERD. As per the modified Savary-Miller grading system, 21 (79\%) had grade I-II esophagitis, 2 patients (7\%) had grade III esophagitis, and 2 (7\%) had grade IV-V esophagitis preoperatively. The remaining 2 patients (7\%), who had type II HH, did not have esophagitis. Preoperative manometry findings included low LES pressures ranging between 5 to $9 \mathrm{~mm} \mathrm{Hg}$ (normal range $=10$ to $25 \mathrm{~mm} \mathrm{Hg}$ ) in 25 patients and normal LES pressures in 2 patients (the 2 type II HH patients). Esophageal motility was normal (i.e., peristaltic wave amplitude in distal esophagus more than $30 \mathrm{mms}$ of $\mathrm{Hg}$ ) in 25 patients and low in 2 patients. These 2 patients had a peristaltic wave amplitude in the distal esophagus of 25 and $28 \mathrm{~mm} \mathrm{Hg}$, respectively. The mean body mass index (BMI) of the patient population in our study was 27 (range:1832). A correlation with BMI (-Table 1) showed significant predilection of $\mathrm{HH}$ with overweight and obese patients (23 patients i.e. 85\% OGDscopy positive and 17 patients i.e. $63 \%$ UGI manometry positive). The preoperative duration of the symptoms was 6 months to 2 years. The average operating time dropped from 130 minutes for the first 12 cases to 90 minutes for the last 15 cases. The mean hospital stay was 3.30 days (range: $2-10$ days). A total of 23 (85\%) patients with low LES pressures but normal esophageal motility underwent laparoscopic Nissen's fundoplication $\left(360^{\circ}\right.$ posterior wrap), whereas 2 patients (7.5\%) with low LES and low esophageal motility underwent laparoscopic Toupet's fundoplication $\left(270^{\circ}\right.$ posterior wrap). The remaining 2 (7.5\%) with normal LES pressures and esophageal motility, but having type II hernia and gastric volvulus, were subjected to laparoscopic cruroplasty + gastropexy.

Five patients had intraoperative complications ( $\mathbf{- T a b l e ~} \mathbf{3}$ ). Two patients had surgical emphysema, which settled without any further intervention over 24 hours. Two patients had port site bleeding, which was stopped with external pressure. One patient had an esophageal perforation, as it was a large tightly incarcerated paraesophageal hernia (stomach and greater omentum were the trapped contents), and gentle attempts at taxis and reduction of the trapped contents led to perforation of the esophagus. This was identified intraoperatively and suture repaired primarily. This patient was kept nil per oral for 5 days and started on NGT feeds thereafter for 15 days. After this period, a barium swallow study was performed, and it showed no leak of contrast. The NGT was then withdrawn, and she was started on semisolid feeds per orally. The length of hospital stay of this patient was 10 days.

At postoperative follow-up, 5 patients (20\%) experienced mild dysphagia to solids in the first 2 weeks after the operation.
Table 3 Intra and postoperative complications

\begin{tabular}{|l|l|}
\hline Intraoperative complications & Number (\%) \\
\hline$>$ Port-site bleeding & $2(7 \%)$ \\
\hline$>$ Significant Hemorrhage & 0 \\
\hline$>$ Esophageal perforation & $1(3.6 \%)$ \\
\hline$>$ Surgical emphysema & $2(7 \%)$ \\
\hline$>$ Pneumothorax & 0 \\
\hline $\begin{array}{l}\text { Early postoperative complications-up to 6 } \\
\text { weeks postop. }\end{array}$ & \\
\hline$>$ Significant hemorrhage & 0 \\
\hline$>$ Wound infection & 0 \\
\hline $\begin{array}{l}>\text { Wrap undoing/slippage/migration/ } \\
\text { herniation }\end{array}$ & 0 \\
\hline Late complications: 6-12 months postop. & \\
\hline $\begin{array}{l}>\text { Wrap undoing/slippage/migration/ } \\
\text { herniation }\end{array}$ & 0 \\
\hline$>$ Required endoscopic dilatation & 0 \\
\hline$>$ Required redo surgery & 0 \\
\hline
\end{tabular}

In three cases, the dysphagia improved by 4 weeks after surgery and did not require any intervention. In the two patients in whom it did not, a barium swallow was performed. In both patients, it showed the wrap in perfect position with a smooth flow of contrast into the stomach without holdup or esophageal dilatation. Both patients were relieved of the dysphagia by 6 weeks. As much as $72 \%(n=18)$ of the patients reported improvement in the GERD symptoms, while 2 (8\%) patients described heartburn (grade 1-2, mild) daily and 1 (4\%) patient described bloating (grade 1-2) daily during the first and fourth follow-up visits. All these symptoms resolved by the 6th week follow-up visit upon the continuation of PPI therapy, after which it was stopped. There was no conversion to open, and we observed no peri-operative mortality. At the time of writing this paper, mean follow-up duration was 28 months. The long term follow up information of our patients is summarized in Table 4. Those who reported typical GERD symptoms during long term follow up were put on an empiric 15 day PPI course. In most patients, the symptoms were relieved with this. Those in whom they persisted(3 patients), underwent a barium swallow to check for position of the wrap. In all 3, the wrap was found to be in optimum position. The PPI course was then optimized and extended for 2 more weeks after which all 3 patients were relieved of their symptoms.

\section{Discussion}

Dr. Rudolph Nissen (1896 to 1981) was the first to perform fundoplication in 1955 and published the result of his two operated cases in a Swiss medical weekly in 1956. However, in 1961, he published a more detailed overview of the procedure originally called "gastroplication." The first LF was described by Dallemagne et al in 1991. ${ }^{3}$ Nissen's LF has changed the way GERD is managed in both adults and children. Nissen's fundoplication is performed to treat GERD and $\mathrm{HH}{ }^{7,8}$ GERD is a common illness that impacts large numbers of the population in the modern era. A minority of patients 
Table 4 Long term follow up information

\begin{tabular}{|c|c|c|c|c|}
\hline $\begin{array}{l}\text { Postoperative } \\
\text { symptom }\end{array}$ & $\begin{array}{l}\text { Follow-up at } 6 \text { months } \\
\text { (27 patients) }\end{array}$ & $\begin{array}{l}\text { Follow-up at } 1 \text { year } \\
\text { ( } 27 \text { patients) }\end{array}$ & $\begin{array}{l}\text { Follow-up at } 2 \text { years } \\
\text { ( } 27 \text { patients) }\end{array}$ & $\begin{array}{l}\text { At the time of writing this } \\
\text { paper ( } 25 \text { patients) }\end{array}$ \\
\hline Heartburn & $\begin{array}{l}2 \text { (7\%: } 1 \text {-grade I and } \\
1 \text {-grade II) }\end{array}$ & \begin{tabular}{|l|}
3 (11\%: 2 -grade I and \\
1 -grade II)
\end{tabular} & 2 (7\%: 2-grade I) & 1 (3.5\%: grade I) \\
\hline Regurgitation & 1 (3.5\%: grade I) & 0 & 1 (3.5\%: grade I) & 1 (3.5\%: grade I) \\
\hline Retrosternal pain & 1 (3.5\%: grade II) & 2 (7\%: grade I) & 1 (3.5\%: grade I) & 0 \\
\hline Dysphagia & 0 & 0 & 0 & 0 \\
\hline Bloating & 0 & 0 & 0 & 0 \\
\hline Persistent cough & 0 & 0 & 0 & 0 \\
\hline
\end{tabular}

with GERD have a constantly weak low pressure LES (less than $6 \mathrm{~mm} \mathrm{Hg}$ ), which allows reflux every time the pressure in the stomach exceeds LES pressure. Chronically decreased LES pressures lead to typical/atypical symptoms. Typical symptoms include heartburn and regurgitation, whereas atypical symptoms include dysphagia, bloating, chest pain, cough, and abdominal pain..$^{9,10}$

The diagnosis of GERD is typically made by corelating symptoms and objective test results. For a patient to be a candidate for LF, preoperative testing, which we advocated in our cases, include 1) upper gastrointestinal (GI) scopy, which is mandatory in all patients. It is an ideal diagnostic tool to evaluate specific details of the esophageal mucosa and can establish the presence or absence of esophagitis, Barrett esophagus, neoplasia, esophageal stricture and also determines gastroesophageal junction flap; 2) esophageal manometry, which is another mandatory test. It is usually performed with a seven-lumen sleeve-side hole catheter. Basal pressure at the LES region is recorded with the sleeve sensor along with the gastric pressure. In resting conditions, LES maintains a high-pressure zone, that is, 15 to $30 \mathrm{~mm} \mathrm{Hg}$ above intragastric pressures, depending on individual variability. A minority of patients with GERD have a constantly weak, low-pressure LES, which permits reflux every time the pressure in the stomach exceeds the LES pressure. This occurs when LES pressure is $<6 \mathrm{~mm} \mathrm{Hg}$. ${ }^{4}$ It is also used to detect esophageal motility. Objective details of esophageal motility influence the degree of wrap, that is, partial or complete wrap; 3) 24 hours impedance-pH monitoring. In our practice, we recommend this test only in the following situations: a) only atypical symptoms, b) normal OGD scopy, and c) PPI non-responders with typical GERD symptoms. Thus, none of the patients in the present study underwent this test. Patients are asked to stop all antireflux medications for 5 days before this test. The $\mathrm{pH}$ probe is positioned $5 \mathrm{~cm}$ above the position of the LES, as determined earlier by manometry. Gastroesophageal reflux is considered as a drop in esophageal $\mathrm{pH}$ below 5 , and the number of such episodes in 24 hours is calculated for each patient and are corelated with their symptoms. ${ }^{9-12}$

The basic goal of treatment should always be to provide symptomatic relief, prevent complications, and improve quality of life. Lifestyle modifications are considered the cornerstone of management and have proven helpful in many patients. Treatment with PPIs or histamine 2 (H2) antagonists can be adequate for patients with occasional, mild symptoms. However, more aggressive therapy is often required. PPIs (e.g., omeprazole, pantoprazole, etc.) and $\mathrm{H} 2$ receptor antagonists (e.g., ranitidine, cimetidine, etc.) complement each other by reducing the production of gastric acid secretion. However, PPIs are considered more potent and effective than $\mathrm{H} 2$ inhibitors. They are particularly valuable for relieving symptoms, preventing recurrence, and promoting healing in endoscopically positive GERD.

An 8-week course of PPIs is the therapy of choice for symptom relief and healing of erosive esophagitis. PPI nonresponders must ensure optimization of PPI therapy by following advice on lifestyle modification, adjusting the timing of the dose, switching to different PPI's, or increasing the dose of the medication. Even after optimization of PPIs, if the patient does not respond to empiric PPI therapy, further investigative evaluation is mandatory. PPIs are recommended for maintenance therapy, including severe erosive GERD. On-demand therapy with a PPI for the long-term is proposed for patients with nonerosive GERD, responding to a PPI as initial therapy. Maintenance PPI therapy should be administered for patients with GERD who continue to have symptoms after the PPI is discontinued and in patients with complications including erosive esophagitis and Barrett's esophagus. ${ }^{9,10}$

The patient can be advised antireflux surgery if there is a drug compliance issue and in young responders to PPI who need to keep taking them for symptom control (to avoid long-term side effects of PPI therapy). ${ }^{13}$ As in other conditions, stringent and appropriate patient selection gives the best long-term results in LF too. It is a known fact that long-term symptom control after laparoscopic antireflux surgery in obese patients is not good. Morbid obese patients with GERD are better served by laparoscopic gastric bypass surgery instead of standalone antireflux surgery. Laparoscopic antireflux surgery is indicated in patients with chronic obstructive pulmonary disease (COPD) (asthma related to reflux or repeated aspiration pneumonia), unable to continue with PPIs due to compliance or adverse effects or long-term costs, and Barrett's esophagus (controversial). The common variants of LF are (a) Nissen's fundoplication: a total posterior $360^{\circ}$ wrap ( $\boldsymbol{- F i g . 2 A}$ ), (b) Toupet's fundoplication: a posterior $270^{\circ}$ wrap ( - Fig. 2B), c) Dor's fundoplication: an anterior $180^{\circ}$ wrap..$^{14-17}$

We performed Nissen's wrap in 23 patients, Toupet's wrap in 2 patients, and cruroplasty + gastropexy in 2 patients. 
A review of literature on various therapeutic options for GERD along with their intercomparisons is summarized (-Table 5).

\section{Conclusion}

LF is a safe and highly effective procedure for a patient with symptoms of GERD, and it gives long-term relief from symptoms. Stringent selection criteria are necessary to optimize the results of surgery. LF leads to a better quality of life and a high index of satisfaction in the majority of patients. Experience is associated with a significant reduction of operating time, hospitalization, and conversion to open surgery.

\section{Note}

Written informed consent was obtained from the patient for publication of this paper.

\section{Conflict of Interest}

None declared.

Table 5 Review of literature on various therapeutic options for GERD and their intercomparisons

\begin{tabular}{|c|c|c|c|c|}
\hline $\begin{array}{l}\text { Authors } \\
\text { (ref. no.) }\end{array}$ & $\begin{array}{l}\text { Journal (year } \\
\text { of publication) }\end{array}$ & $\begin{array}{l}\text { Type of } \\
\text { study } \\
\text { (no. of pts.) }\end{array}$ & Materials/methods & Conclusions \\
\hline Frazzoni et al ${ }^{15}$ & WJG (2014) & Review & Describes all types of GERD & $\begin{array}{l}\text { Stress on impedance } \mathrm{pH} \text { monitoring as the diagnos- } \\
\text { tic decision-making tool }\end{array}$ \\
\hline Viswanath et $\mathrm{al}^{7}$ & $\begin{array}{l}\text { Frontline GE } \\
(2019)\end{array}$ & $\begin{array}{l}\text { Prospective } \\
\text { study: } \\
\text { case series }\end{array}$ & $\begin{array}{l}50 \text { patients., study of Stretta } \\
\text { procedure for refractory GERD }\end{array}$ & $\begin{array}{l}\text { Improved quality of life and reduced PPI depend- } \\
\text { ency in selected patients-good option for patients } \\
\text { who are unwilling or unable to undergo surgery }\end{array}$ \\
\hline $\begin{array}{l}\text { Stefanidis } \\
\text { et } \text { al }^{16}\end{array}$ & $\begin{array}{l}\text { SAGES position } \\
\text { doc (2017) }\end{array}$ & $\begin{array}{l}\text { Meta- } \\
\text { analyses }\end{array}$ & \begin{tabular}{|l|} 
Meta-analysis of publications on \\
esophyx and Stretta procedures \\
Esophyx-60 papers, Stretta-117 \\
papers
\end{tabular} & $\begin{array}{l}\text { Symptom control better with esophyx and Stretta } \\
\text { than PPI, but results of LNF are superior to both; } \\
\text { Stretta has fewer complications. Also, Stretta has a } \\
\text { role in therapy in operated patients with recovery of } \\
\text { symptoms }\end{array}$ \\
\hline $\begin{array}{l}\text { Schoppmann et } \\
\mathrm{al}^{14}\end{array}$ & $\begin{array}{l}\text { Translational } \\
\text { Gastroenterology } \\
\text { and Hepatology } \\
\text { (2018) }\end{array}$ & Meta-analysis & 8 cohorts and 1 RCT analyzed & $\begin{array}{l}\text { Antireflux surgery and ablative endotherapy disrupt } \\
\text { progression of Barrett's into cancer }\end{array}$ \\
\hline $\begin{array}{l}\text { Livingston } \\
\text { et } \mathrm{al}^{13}\end{array}$ & $\begin{array}{l}\text { The American } \\
\text { Surgeon } \\
(2001)\end{array}$ & 188 patients & $\begin{array}{l}\text { Comparison between LNF vs. } \\
\text { Toupet's in type I and II HHs }\end{array}$ & $\begin{array}{l}\text { Low rate of dysphagia with Toupet's, symptom } \\
\text { control better and longer lasting with LNF. Similar } \\
\text { recovery rate of symptoms in Toupet vs. LNF when } \\
\text { both associated with type II HH repair }\end{array}$ \\
\hline Reynolds ${ }^{12}$ & $\begin{array}{l}\text { Canadian } \\
\text { Journal of } \\
\text { Gastroenterology } \\
(2007)\end{array}$ & Review & \begin{tabular}{|l|} 
Statement of indications for \\
24-hour $\mathrm{pH}$ monitoring, its com- \\
parison with the wireless system \\
vis-à-vis costs, complications, and \\
pt. tolerance
\end{tabular} & $\begin{array}{l}\text { Valuable tool in diagnostic uncertainty but of no } \\
\text { value in endoscopy-positive GERD and in those } \\
\text { classical symptoms responding to PPIs }\end{array}$ \\
\hline $\begin{array}{l}\text { Cardenas } \\
\text { et al }{ }^{11}\end{array}$ & $\begin{array}{l}\text { Revista de gas- } \\
\text { troenterologya } \\
\text { de Mexico } \\
(2005)\end{array}$ & $\begin{array}{l}\text { Comparative } \\
\text { study } \\
(241)\end{array}$ & $\begin{array}{l}\text { LNF vs. Nissen-Rosetti's vs. } \\
\text { Toupet's }\end{array}$ & $\begin{array}{l}\text { - LNF-best results } \\
\text { - Nissen-Rosetti's more dysphagia and reoperation } \\
\text { rate } \\
\text { - Toupet's more symptom recovery }\end{array}$ \\
\hline $\begin{array}{l}\text { Tolone } \\
\text { et al }{ }^{10}\end{array}$ & $\begin{array}{l}\text { World Journal of } \\
\text { Gastrointestinal } \\
\text { Surgery } \\
(2016)\end{array}$ & Meta-analysis & \begin{tabular}{|l|} 
Patients of GERD analyzed based \\
on presence/absence of classical \\
symptoms, HH, Barrett's, \\
PPI response, endoscopic-pos- \\
itive signs. Also, instrumental \\
features of motility, esophageal \\
acid exposure, and impedance pH \\
monitoring also factored in
\end{tabular} & $\begin{array}{l}\text { - Patients with classical symptoms, presence of HH, } \\
\text { endoscopic features, Barrett's, and PPI responders } \\
\text { have better results with antireflux surgery. } \\
\text { - Those without the above should be investigated } \\
\text { further by impedance pH monitoring due to its } \\
\text { ability to better identify reflux-symptom association } \\
\text { before surgery }\end{array}$ \\
\hline Schietroma et al ${ }^{9}$ & $\begin{array}{l}\text { Journal of } \\
\text { Obesity } \\
(2017)\end{array}$ & $\begin{array}{l}\text { Research } \\
\text { article } \\
(728)\end{array}$ & $\begin{array}{l}\text { Comparison of patient demo- } \\
\text { graphics, operative and postop- } \\
\text { erative outcomes, conversion to } \\
\text { open, complications, and long- } \\
\text { term follow-up done }\end{array}$ & $\begin{array}{l}\text { BMI does not influence short-term outcomes, but } \\
\text { long-term reflux control in the obese after LNF is } \\
\text { worse than in normal weight patients. }\end{array}$ \\
\hline Janu et al ${ }^{8}$ & $\begin{array}{l}\text { Surgical } \\
\text { Innovation } \\
(2019)\end{array}$ & $\begin{array}{l}\text { Prospective } \\
\text { study } \\
(99)\end{array}$ & $\begin{array}{l}\text { Laparoscopy HH repair + esophyx } \\
\text { performed in those with } \mathrm{HH} 2-5 \\
\text { cm: HRQoL, surgical outcomes } \\
\text { studied }\end{array}$ & $\begin{array}{l}\text { Significant symptom controls up to } 12 \text { months, no } \\
\text { long-term gas bloat or dysphagia }\end{array}$ \\
\hline
\end{tabular}

Abbreviations: BMI, body mass index; $\mathrm{HH}$, hiatus hernia; GERD, gastroesophageal reflux disease; HRQoL, health-related quality of life; LNF, laparoscopic Nissen's fundoplication; PPI, proton-pump inhibitor ; RCT, randomized control trial; WJG, World Journal of Gastroenterology; GE, gastroenterology; SAGES, Society of American Gastrointestinal Endoscopic Surgeons. 


\section{References}

1 Dent J, El-Serag HB, Wallander MA, Johansson S. Epidemiology of gastro-oesophageal reflux disease: a systematic review. Gut 2005;54(5):710-717

2 Alain FRG, Elizabeth FE. Enfermedad por reflujogastroesofágico. Rev Mex Cirug Apar Diges. 2016;5(3):96-105

3 Dallemagne B, Weerts JM, Jehaes C, Markiewicz S, Lombard R. Laparoscopic Nissen fundoplication: preliminary report. Surg Laparosc Endosc 1991;1(3):138-143

4 Richter J. Do we know the cause of reflux disease? Eur J Gastroenterol Hepatol 1999;11(Suppl 1):S3-S9

5 Jaynes M, Kumar AB. The risks of long-term use of proton pump inhibitors: a critical review. Ther Adv Drug Saf 2018;10:2042098618809927

6 Kinoshita Y, Ishimura N, Ishihara S. Advantages and disadvantages of long-term proton pump inhibitor use. J Neurogastroenterol Motil 2018;24(2):182-196

7 Viswanath YKS, et al. Endoscopic day case antireflux radiofrequency (Stretta) therapy improves quality of life and reduce proton pump inhibitor (PPI) dependency in patients with gastro-oesophageal reflux disease: a prospective study from a UK tertiary centre. Frontline Gastroenterol 2019;10(2):113-119

8 Janu P, Shughoury AB, Venkat K, et al. Laparoscopic hiatal hernia repair followed by transoral incisionless fundoplication with EsophyX Device (HH + TIF): efficacy and safety in two community hospitals. Surg Innov 2019;26(6):675-686
9 Schietroma M, Piccione F, Clementi M, et al. Short- and long-term, 11-22 years, results after laparoscopic nissen fundoplication in obese versus nonobese patients. J Obes 2017;2017:7589408

10 Tolone S, Gualtieri G, Savarino E, et al. Pre-operative clinical and instrumental factors as antireflux surgery outcome predictors. World J Gastrointest Surg 2016;8(11):719-728

11 Gómez Cárdenas X, Flores Armenta JH, Elizalde Di Martino A, et al. [Antireflux surgery, comperative study of three laparascopic techniques]. Rev Gastroenterol Mex 2005;70(4):402-410

12 Reynolds RPE. pH studies: clinical indications. Can J Gastroenterol 2007;21(11):697-698

13 Livingston CD, Jones HLJr, Askew REJr, Victor BE, Askew RE Sr. Laparoscopic hiatal hernia repair in patients with poor esophageal motility or paraesophageal herniation. Am Surg 2001;67(10):987-991

14 Schoppmann SF, Kristo I, Riegler M. Does anti-reflux surgery disrupt the pathway of Barrett's esophagus progression to cancer? Transl Gastroenterol Hepatol 2018;3:101

15 Frazzoni M, Piccoli M, Conigliaro R, Frazzoni L, Melotti G. Laparoscopic fundoplication for gastroesophageal reflux disease. World J Gastroenterol 2014;20(39):14272-14279

16 Stefanidis D, Richardson W, Farrell TM, Kohn GP, Augenstein V, Fanelli RD; Society of American Gastrointestinal and Endoscopic Surgeons. SAGES guidelines for the surgical treatment of esophageal achalasia. Surg Endosc 2012;26(2):296-311

17 Katz PO, Gerson LB, Vela MF. Guidelines for the diagnosis and management of gastroesophageal reflux disease. Am J Gastroenterol 2013;108(3):308-328 